\title{
A Comparative Study of Oral Health Parameters in Molar Incisor Hypomineralization and High-Caries-Risk Children Aged 8-11 Years
}

\author{
Ayca Tuba Ulusoy ${ }^{a}$ Emine Sen Tunc ${ }^{a}$ Şule Bayrak ${ }^{c}$ Hasan Onder ${ }^{b}$ \\ ${ }^{a}$ Department of Pediatric Dentistry, Faculty of Dentistry, and bepartment of Animal Science Biometry and \\ Genetics, Faculty of Agriculture, Ondokuz Mayis University, Samsun, and ' Faculty of Dentistry, University of \\ Osmangazi, Eskişehir, Turkey
}

\section{Key Words}

Caries · Molar incisor hypomineralization · Oral health

\begin{abstract}
Objective: To compare oral health parameters: decayed missing filled teeth (dmft, DMFT), gingival index and plaque index in high-caries-risk children and children with molar incisor hypomineralization (MIH). Subjects and Methods: $\mathrm{A}$ study group of 81 children affected by MIH ( 49 girls, 32 boys) aged 8-11 years (mean $9.4 \pm 1.1$ ) was race-, age- and sexmatched with 81 high-caries-risk children not affected by $\mathrm{MIH}$ (controls). The MIH and control groups were divided into four subgroups according to age. The oral health parameters of both groups were recorded under clinical conditions. Mann-Whitney $U$ and Kruskal-Wallis tests were used to compare the differences in the number of $\mathrm{MIH}$-affected teeth between the groups. Other traits were evaluated with the ANOVA test, and Duncan's multiple comparison tests were used for comparing means. Linear and ordinal regression analyses were used to model the variables. Results: The mean age of the participants was $9.4 \pm 1.1$ years, and the mean number of affected teeth was 7.7 (range 3-12) in the $\mathrm{MIH}$ group. The number of affected teeth and severity of $\mathrm{MIH}$ did not change significantly with age and sex ( $p>0.05)$. A comparison of the oral health parameters of $\mathrm{MIH}$-affected and control children according to groups did not show any
\end{abstract}

statistically significant differences between the groups for all parameters for all groups ( $p>0.05$ ) with the exception of DMFT values at 10 years of age $(p<0.05)$. In a comparison of the total scores without taking age into account, the children with MIH showed a significantly higher DMFT value than the children without MIH ( $p<0.05)$, but there were no significant differences between the $\mathrm{dmft}, \mathrm{Gl}$ and PI values of the study groups ( $p>0.05)$. Conclusion: The children in the MIH group had higher DMFT than those without MIH. Hence, the presence of MIH could have a detrimental effect on oral health parameters, especially on DMFT values.

(C) 2015 S. Karger AG, Basel

\section{Introduction}

In 2001, the term molar incisor hypomineralization (MIH) was coined to describe a specific clinical condition caused by a disturbance in the early phase of enamel maturation in one or more permanent first molars, with or without the involvement of permanent incisors [1]. The prevalence of MIH is reported to vary between 2.4 and $40.2 \%$ in normal child populations [2], and it was reported that the prevalence in Turkish children was $7.7 \%$, which is within the above range [3]. While the etiology of $\mathrm{MIH}$ is not fully understood, $\mathrm{MIH}$ has been linked to environmental changes, including pre- and

\begin{tabular}{ll}
\hline KARGER & $\begin{array}{l}\text { C) } 2015 \text { S. Karger AG, Basel } \\
1011-7571 / 15 / 0251-0085 \$ 39.50 / 0 \quad \text { Karger }\end{array}$ \\
$\begin{array}{l}\text { E-Mail karger@karger.com } \\
\text { www.karger.com/mpp }\end{array}$ & $\begin{array}{l}\text { This is an Open Access article licensed under the terms of the } \\
\text { Creative Commons Attribution-NonCommercial 3.0 Un- } \\
\text { ported license (CC BY-NC) (www.karger.com/OA-license), } \\
\text { applicable to the online version of the article only. Distribu- } \\
\text { tion permitted for non-commercial purposes only. }\end{array}$
\end{tabular}

Emine Sen Tunc

Department of Pediatric Dentistry

Faculty of Dentistry, Ondokuz Mayis University

TR-55139 Samsun (Turkey)

E-Mail sentunc@yahoo.com 
perinatal problems, prolonged breastfeeding, respiratory disease, diseases characterized by high fever (such as chicken pox) and the frequent use of antibiotics in early childhood [3-6]. However, no single etiological factor has yet been linked conclusively to the development of this disease.

Clinically, the most common problems for patients with $\mathrm{MIH}$ are attrition, exposed dentin, atypical cavities or complete coronal distortion and high sensitivity to temperature variation and toothbrushing [7]. The MIH enamel defects vary in color from white to yellow/brownish, but a sharp demarcation is always observed between the affected enamel and sound enamel $[1,8]$. Tooth surface enamel initially develops to a normal thickness, but it is easily fractured under masticatory forces, predisposing it to the unexpected development of fast caries [9]. For this reason, MIH defects are considered a caries risk factor in populations with a low prevalence of caries [10]. Moreover, hypomineralization influences a child's toothbrushing ability, causing pain and discomfort for the child and resulting in a high level of plaque accumulation and dental caries [7]. Toothbrushing is the primary contributor to good oral hygiene and is crucial for the maintenance of gingival and periodontal health $[11,12]$. Gingival health and caries should both be carefully considered when assessing the dental health of children and young adolescents. Therefore, this study aimed to investigate dental health in a group of children in northern Turkey with MIH and to compare this to a matched control group of children with high caries risk.

\section{Materials and Methods}

\section{Study Population}

The research protocol was approved by the Human Subjects Ethics Committee, and informed written consent was obtained from the parents of all the study participants. The study was carried out at the Department of Pediatric Dentistry of the Ondokuz Mayis University Faculty of Dentistry in Samsun, Turkey. The study population included 81 children (49 girls, 32 boys) aged $8-11$ years who presented between 2010 and 2012 with hypomineralized teeth at the first visit and who were diagnosed as having MIH and a high risk of caries based on the caries-risk assessment tool [13], as well as 81 sex- and age-matched high-caries-active patients not manifesting hypomineralization being treated at the department during the same period (control group). Chronological ages for each subject were calculated by subtracting the date of clinical observation from the date of birth after converting both the decimal ages, and the children were then classified according to age group. To choose the control group, caries risk assessment was done using the caries-risk assessment tool [13]. Inclusion criteria were as follows: (1) children with all first permanent molars and permanent incisors fully erupted and (2) children born and living in Samsun, Turkey, where the fluoride level of tap water is below $0.1 \mathrm{ppm}$. Exclusion criteria were the following: (1) children with developmental enamel defects caused by amelogenesis imperfecta, dental fluorosis, local trauma or major general health disturbances and (2) children currently under orthodontic treatment.

\section{Dental Examinations}

Examinations were performed by an experienced pediatric dentist (A.T.U.) under standard dental lighting using plain mouth mirrors and a ball-ended periodontal probe. The teeth were lightly dried before inspection.

$\mathrm{MIH}$ was diagnosed using the criteria proposed by the European Academy of Pediatric Dentistry [14]. Hypomineralized lesions with a diameter of $<1 \mathrm{~mm}$ were not recorded. Teeth with demarcated opacities that did not need treatment were considered to have 'mild' lesions, teeth with rough and broken enamel were considered to have 'moderate' lesions, and those with hypomineralized lesions associated with the loss of both the enamel and dentin structure, atypical restorations replacing affected hard tissue or extracted due to severe hypomineralization were considered to have 'severe' lesions. Each child was graded for hypomineralization according to the most severe defect seen in his/her permanent first molars or permanent incisors, so that patients with mild lesions but no evidence of moderate or severe lesions were classified as 'mild', those with any moderate lesions but no severe lesions were classified as 'moderate', and those with any severe lesions were classified as 'severe' [15].

Clinical examinations included an assessment of teeth and gingival tissue for decay and oral hygiene. All erupted teeth were assessed using indices of decayed/missing/filled teeth (dmft, DMFT; lowercase letters for primary teeth, uppercase letters for permanent teeth). Oral hygiene examinations were conducted using Community Periodontal Index for Treatment Needs (CPITN) CPI probes, and assessments were made using 2 standard epidemiological indices, the gingival index (GI) [16] and the plaque index (PI) [17]. Erupting permanent teeth and exfoliating primary teeth were excluded from gingival evaluations. The GI was scored as follows: no inflammation - 0 ; mild inflammation, slight change in color, slight edema, no bleeding on probing - 1; moderate inflammation, moderate glazing, redness, bleeding on probing -2 ; severe inflammation, marked redness and hypertrophy, ulceration, tendency to spontaneous bleeding - 3. The PI was scored as follows: no plaque - 0 ; a film of plaque adhering to the free gingival margin and adjacent area of the tooth, which cannot be seen with the naked eye but only by using disclosing solution or probe -1 ; moderate accumulation of deposits within the gingival pocket, on the gingival margin and/or adjacent tooth surface, which can be seen with the naked eye -2 ; abundance of soft matter within the gingival pocket and/or on the tooth and gingival margin -3 .

\section{Statistical Analysis}

Data were analyzed using SPSS version 16.0 (SPSS Inc., Chicago, Ill., USA). The Kolmogorov-Smirnov one-sample test was applied to evaluate the distribution of variables and the Levene test was used to evaluate the homoscedasticity. Data for the number of affected teeth were found to be nonnormally distributed; MannWhitney $U$ and Kruskal-Wallis tests which are nonparametric tests on independent samples were used to compare the differences between the groups because of unrepeated data. Other traits 
Table 1. Distribution of $\mathrm{MIH}$ according to sex and age and the number of teeth affected by MIH $(\mathrm{n}=81)$

\begin{tabular}{lclll}
\hline $\begin{array}{l}\text { Age, } \\
\text { years }\end{array}$ & $\begin{array}{l}\text { Boys, } \\
\mathrm{n}(\%)\end{array}$ & $\begin{array}{l}\text { Girls, } \\
\mathrm{n}(\%)\end{array}$ & Mean \pm SD & $\begin{array}{l}\text { Median } \\
\text { (range) }\end{array}$ \\
\hline $8.0-8.9$ & $6(30)$ & $14(70)$ & $7.3 \pm 0.51$ & $7(4-12)$ \\
$9.0-9.9$ & $10(47.6)$ & $11(52.4)$ & $7.6 \pm 0.49$ & $7(4-12)$ \\
$10.0-10.9$ & $8(42.1)$ & $11(57.9)$ & $7.8 \pm 0.53$ & $8(3-12)$ \\
$11.0-11.9$ & $8(38.1)$ & $13(61.9)$ & $8.0 \pm 0.61$ & $8(3-12)$ \\
\hline Total & $32(39.5)$ & $49(61.5)$ & $7.7 \pm 0.57$ & $8(3-12)$ \\
\hline
\end{tabular}

Kruskal-Wallis test result: $\mathrm{p}=0.808$.

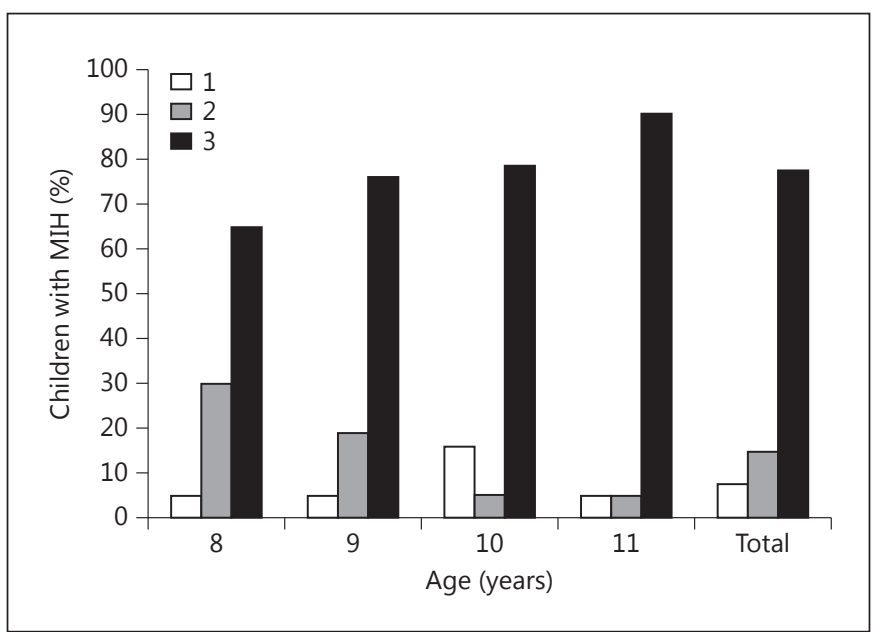

Fig. 1. Percentages of MIH cases rated severe (3), mild (2) and moderate (1) according to clinical data, by age.

were evaluated with the ANOVA test, and Duncan's multiple comparison test was used for comparing means. Linear regression analysis was used to model the variables $\mathrm{dmft}$, DMFT, GI and PI by age and sex effects. In addition, ordinal logistic regression was used to determine the risk factors (age and sex) on odds ratios.

\section{Results}

The distribution of MIH patients according to age and sex can be seen in table 1 . Mean age at the time of the clinical examination was $9.4 \pm 1.1$ years for both the $\mathrm{MIH}$ and control groups. Of the $81 \mathrm{MIH}$-affected children, 72 (90\%) had four affected molars and at least one incisor, 4 (5\%) had only four affected molars, 2 (2.5\%) had only three affected molars, and $3(2.5 \%)$ had only two affected molars.

Oral Health Parameters in MIH and Caries Activity
Table 2. MIH correlation with dmft, DMFT, GI and PI, by age

\begin{tabular}{|c|c|c|c|c|}
\hline $\begin{array}{l}\text { Dental } \\
\text { parameter }\end{array}$ & Age, years & $\begin{array}{l}\text { MIH cases } \\
(\text { mean } \pm \text { SD })\end{array}$ & $\begin{array}{l}\text { Controls } \\
(\text { mean } \pm \mathrm{SD})\end{array}$ & $\mathrm{p}$ value \\
\hline \multirow[t]{5}{*}{$\mathrm{dmft}$} & $8.0-8.9$ & $5.3 \pm 0.52$ & $4.4 \pm 0.48$ & 0.24 \\
\hline & $9.0-9.9$ & $3.3 \pm 0.53$ & $4.4 \pm 0.52$ & 0.13 \\
\hline & $10.0-10.9$ & $4 \pm 0.62$ & $2.8 \pm 0.53$ & 0.15 \\
\hline & $11.0-11.0$ & $1.9 \pm 0.61$ & $1.4 \pm 0.47$ & 0.50 \\
\hline & Total & $3.1 \pm 0.28$ & $3.8 \pm 0.31$ & 0.09 \\
\hline \multirow[t]{5}{*}{ DMFT } & $8.0-8.9$ & $3 \pm 0.3$ & $2.1 \pm 0.39$ & 0.08 \\
\hline & $9.0-9.9$ & $3.1 \pm 0.28$ & $2.3 \pm 0.36$ & 0.15 \\
\hline & $10.0-10.9$ & $4.1 \pm 0.61$ & $2.5 \pm 0.44$ & $0.05^{*}$ \\
\hline & $11.0-11.0$ & $3.7 \pm 0.52$ & $3.6 \pm 0.38$ & 0.87 \\
\hline & Total & $3.4 \pm 0.23$ & $2.6 \pm 0.20$ & $0.008^{*}$ \\
\hline \multirow{5}{*}{ GI } & $8.0-8.9$ & $0.35 \pm 0.09$ & $0.32 \pm 0.1$ & 0.84 \\
\hline & $9.0-9.9$ & $0.33 \pm 0.11$ & $0.23 \pm 0.07$ & 0.35 \\
\hline & $10.0-10.9$ & $0.47 \pm 0.11$ & $0.43 \pm 0.1$ & 0.84 \\
\hline & $11.0-11.0$ & $0.4 \pm 0.11$ & $0.32 \pm 0.1$ & 0.57 \\
\hline & Total & $0.35 \pm 0.05$ & $0.36 \pm 0.05$ & 0.93 \\
\hline \multirow[t]{5}{*}{ PI } & $8.0-8.9$ & $0.51 \pm 0.09$ & $0.46 \pm 0.09$ & 0.71 \\
\hline & $9.0-9.9$ & $0.55 \pm 0.11$ & $0.4 \pm 0.09$ & 0.3 \\
\hline & $10.0-10.9$ & $0.76 \pm 0.12$ & $0.56 \pm 0.1$ & 0.22 \\
\hline & $11.0-11.0$ & $0.58 \pm 0.15$ & $0.56 \pm 0.12$ & 0.91 \\
\hline & Total & $0.5 \pm 0.05$ & $0.60 \pm 0.05$ & 0.21 \\
\hline
\end{tabular}

The mean number of MIH teeth affected was $7.7 \pm 0.57$ (range 3-12) per individual child. Although the number of affected teeth increased with age, this increase was not statistically significant $(\mathrm{p}=0.808$; table 1$)$. In addition, ordinal logistic regression analysis results revealed that there was no effect of age on the number of affected teeth.

The score of severity was observed most when the MIH cases were the most prevalent type at each age (fig. 1), and based on ordinal logistic regression analysis age had no significant effect on the severity of MIH.

Oral health information on dental caries, dental plaque and gingivitis is given in table 2. A comparison of the other oral health parameters of MIH of the affected children and the controls, based on age groups, did not show any statistically significant differences between the subgroups for all parameters for all age groups $(p>0.05)$ with the exception of DMFT values of children at 10 years of age $(4.1 \pm 0.61$ for MIH group and $2.5 \pm 0.44$ for control group; $\mathrm{p}<0.05)$. In a comparison of the total scores without taking age into account, the children with $\mathrm{MIH}$ showed a significantly higher DMFT value than the chil- 
dren without MIH ( $p<0.05)$, but there were no significant differences between $\mathrm{dmft}$, GI and PI values of the study groups $(p>0.05)$. Linear regression analysis revealed that sex and age did not significantly affect oral health parameters in the MIH group.

\section{Discussion}

The main finding of this study was that MIH had a detrimental effect on DMFT compared to the controls.

Optimal dental health can be obtained when appropriate oral hygiene practices and other dental behavior are maintained in conjunction with a low cariogenic diet in the presence of adequate saliva. Individual oral health care mainly involves daily oral hygiene practices, including toothbrushing and flossing, combined with regular cleaning and care at a dental clinic $[11,12]$. A tooth with a defect is often difficult to clean, and poor daily oral care can not only worsen the clinical status of a defective tooth but can also have a negative impact on the remaining sound tooth structure, thereby increasing the need for treatment [18]. MIH is known to predispose an affected tooth surface to plaque accumulation and sensitivity and may possibly contribute to the development of dental caries $[7,15]$. Earlier MIH studies have examined this issue without stratifying the caries risk assessment of the control groups. Only a few studies comprised low- and medium-caries-risk children as a control group [15, 19-23]. However, given that enamel defects represent one of the major risk indicators for caries [13], this study was conducted with a control group comprised of high-cariesrisk children.

In this study the mean number of MIH-affected teeth (7.7 \pm 0.5$)$ was higher than those of previous studies (2.6$5.6)[8,20-22,24]$. The differences in findings may be due to the differences in examination conditions. The majority of MIH studies $[8,19-22,24,25]$ were comprised of school children for whom it was not possible to obtain detailed examinations, but in our study the patients were from the Pediatric Dental Clinic, and intraoral examinations were done under well-controlled clinical conditions.

According to the results the nonsignificant increase in the number of MIH-affected teeth with age might be explained by the slight increase in the number of eruptions of affected teeth. Nearly $80 \%$ of MIH cases in this study were classified as severe. The nonsignificant increase in the number of severe cases may be explained by the nature of hypomineralized lesions: as children grow older, predisposing conditions tend not to reverse themselves, and latent defects become visible or worsen in the oral environment [26]. Therefore, if any hypomineralized tooth worsened with time, MIH severity was recorded according to this tooth.

Studies have long been conducted to try to determine the relationship between MIH and caries [15, 19-27]. Although many studies reported increasing rates of caries and treatment requirements in teeth affected by $\mathrm{MIH}[15$, 19-22], a more recent study by Heitmüller et al. [27] did not find a significant relationship between $\mathrm{MIH}$ and caries in 10-year-old children. Similar to former studies, the present study showed that children affected by MIH tended to have a higher number of caries than their controls. The present study also found that $\mathrm{dmft}$ values of both groups decreased with age, while DMFT values of both groups increased with age. This finding is not surprising, given that the number of permanent teeth increases with age.

The results showed that although there were no significant differences in both PI and GI values between the MIH and control groups, the MIH group tended to be worse with regard to gingival health parameters. This can be attributed to the fact that defective enamel causes patient sensitivity while brushing, resulting in a high level of plaque accumulation [1] in the MIH group.

\section{Conclusion}

The prevalence of MIH was high and hence could have a detrimental effect on oral health parameters, especially on DMFT values.

\footnotetext{
References $\longrightarrow$ Weerheijm KL, Jalevik B, Alaluusua S: Molarincisor hypomineralisation. Caries Res 2001; 35:390-391.

2 Jalevik B: Prevalence and diagnosis of molarincisor hypomineralisation (MIH): a systematic review. Eur Arch Paediatr Dent 2010;11: 59-64.

-3 Sönmez H, Yıldırım G, Bezgin T: Putative factors associated with molar incisor hypomineralisation: an epidemiological study. Eur Arch Paediatr Dent 2013;14:375-380.

4 Weerheijm KL: Molar-incisor hypomineralisation. Eur J Paediatr Dent 2003;35:390-391.

5 Alaluusua S: Aetiology of molar-incisor hypomineralisation: a systematic review. Eur Arch Paediatr Dent 2010;11:53-58.

-6 Alaluusua S, Lukinmaa P-L, Koskimies M, et al: Developmental enamel defects associated with long breast feeding. Eur J Oral Sci 1996; 104:493-497.
}

Ulusoy/Sen Tunc/Bayrak/Onder 
7 Jälevik B, Klingberg GA: Dental treatment, dental fear and behaviour management problems in children with severe enamel hypomineralization of their permanent first molars. Int J Paediatr Dent 2002;12:1224-1232.

$>8$ Jälevik B, Klingberg G, Barregård L, et al: The prevalence of demarcated opacities in permanent first molars in a group of Swedish children. Acta Odontol Scand 2001;59:255-260.

$\checkmark 9$ Mathu-Muju K, Wright JT: Diagnosis and treatment of molar incisor hypomineralization. Compend Contin Educ Dent 2006;27: 604-611.

-10 Elfrink ME, Schuller AA, Veerkamp JS, et al: Factors increasing the caries risk of second primary molars in 5-year-old Dutch children. Int J Paediatr Dent 2010;20:151-157.

$>11$ Attin T, Hornecker E: Tooth brushing and oral health: how frequently and when should tooth brushing be performed? Oral Health Prev Dent 2005;3:135-140.

-12 Al-Shammari KF, Al-Ansari JM, Al-Khabbaz AK, et al: Self-reported oral hygiene habits and oral health problems of Kuwaiti adults. Med Princ Pract 2007;16:15-21.

13 American Academy of Pediatric Dentistry: CAT: Guideline on Caries-risk Assessment and Management for Infants, Children, and Adolescents 2014. Chicago, AAPD, 2014.
14 Weerheijm KL, Duggal M, Mejàre I, et al: Judgement criteria for molar incisor hypomineralisation (MIH) in epidemiologic studies: a summary of the European meeting on MIH held in Athens, 2003. Eur J Paediatr Dent 2008;4:110-113.

15 Leppäniemi A, Lukinmaa PL, Alaluusua S: Nonfluoride hypomineralizations in the permanent first molars and their impact on the treatment need. Caries Res 2001;35:36-40.

16 Löe H, Silness J: Periodontal disease in pregnancy. I. Prevalence and severity. Acta Odontol Scand 1963;21:533-551.

17 Silness J, Loe H: Periodontal disease in pregnancy. II. Correlation between oral hygiene and periodontal condition. Acta Odontol Scand 1964;22:121-135.

18 Targino AG, Rosenblatt A, Oliveira AF, et al: The relationship of enamel defects and caries: a cohort study. Oral Dis 2011;17:420-426.

19 Preusser SE, Ferring V, Wleklinski C, et al: Prevalence and severity of molar incisor hypomineralization in a region of Germany - a brief communication. J Public Health Dent 2007;67:148-150.

20 Muratbegovic A, Markovic N, Ganibegovic Selimovic M: Molar incisor hypomineralisation in Bosnia and Herzegovina: aetiology and clinical consequences in medium caries activity population. Eur Arch Paediatr Dent 2007;8:189-194.
21 Muratbegovic A, Markovic N, Kobalija S, et al: Oral health indices and molar incisor hypomineralization in 12-year-old Bosnians. Acta Stomatol Croat 2008;42:155-163.

22 Cho SY, Ki Y, Chu V: Molar incisor hypomineralization in Hong Kong Chinese children. Int J Paediatr Dent 2008;18:348-352.

23 Brogårdh-Roth S, Matsson L, Klingberg G: Molar-incisor hypomineralization and oral hygiene in 10- to-12-year-old Swedish children born preterm. Eur J Oral Sci 2011;119: 33-39.

24 Jeremias F, de Souza JF, Silva CM, et al: Dental caries experience and molar-incisor hypomineralization. Acta Odontol Scand 2013;71: 870-876.

25 Ghanim AM, Manton DJ, Morgan MV, et al: Trends of oral health care and dental treatment needs in relation to molar incisor hypomineralisation defects: a study amongst a group of Iraqi schoolchildren. Eur Arch Paediatr Dent 2012;13:171-178.

26 Fitzpatric L, O’Connell A: First permanent molars with molar incisor hypomineralisation. J Ir Dent Assoc 2007;53:32-37.

27 Heitmüller D, Thiering E, Hoffmann U, et al: Is there a positive relationship between molar incisor hypomineralisations and the presence of dental caries? Int J Paediatr Dent 2013;23: $116-124$. 